eral interpretation, the difference would have been only two or three per cent.

I am very glad to know that Mr. Clayton verifies his predictions of three elements by only two of them, and this gives us an interesting verification of the predictions given in my first letter. If we count ' rain' $=$. OI of an inch or more, and apply this to Mr. Clayton's predictions, (I), we shall find that they verify 80 per cent; applying to mine, (2), 96 per cent. But Mr. Clayton's predictions were not made to be verified by this rule, so we must fall back on his official figures, which are 85 per cent.

If any thing has been brought out most clearly by this discussion, it is the absolute need of a thorough examination of the method of prediction in each case ; and if a comparison is to be instituted, it should only be after a careful formulation of a method which shall give a fair test of the nearness of the prediction to the actual weather experienced, taking into account as far as possible the language used in each prediction. I know it to be a fact that a person may give the same prediction for a place in two different terms, and a seeming application of the same rules to both will give a difference of more than 35 per cent in the two verifications.

H. A. HAZEN.

Washington, D.C., Jan. 20.

\section{Children's Development.}

Apropos of the letter of ' $G$.' on children's development, in Science of Jan. I3, I was led to make the following contribution. When my little daughter was eighteen months old, I wrote down her vocabulary, as far as was possible, a number of days being spent in the process, so that it may be assumed that it is nearly complete. The total number of words is four hundred and sixtynine, divided as follows :-

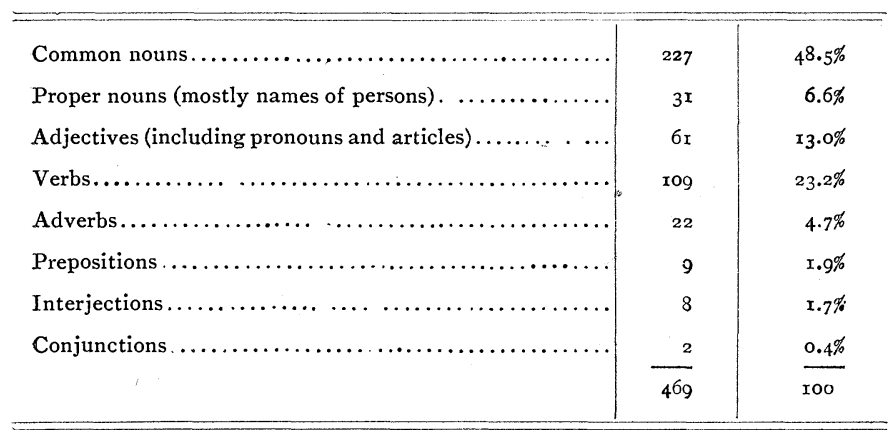

These were all words used by the child spontaneously, and in approximately their correct signification. Only one part of a verb is counted, unless the verbal stems of the different parts are distinct; plurals are not separately counted; and words used both as nouns and verbs are counted only once. The percentages are not materially different from those in the case cited by 'G.,' but further contributions on this point seem desirable.

Louisville, Ky., Jan. $x 8$.

J. L. H.

\section{Sections of Fossils.}

Mr. Foerste, in No. 258 of Science, quotes from letters from Professor Prestwich and Dr. Geikie in regard to sections of Bryozoa. In referring to these authors in No. 250 of Science, I did so simply to call attention to what they say in regard to rock-sections in general, not Bryozoa in particular. It is not worth while to say more upon this point. In regard to my reference to Dr. Nicholson's work, I never inferred "that Professor Nicholson does not believe in the use of these microscopic sections," but that he stated in numerous places in both his volumes on fossil corals that in many cases it is not possible to separate species on internal structure, so recourse is had to external features; and from this fact I contend that the internal structure of these organisms is not sufficient to separate species. The old school, if it may be so called, as opposed to the new, believe that internal characters are often misleading, and that external features may more safely be followed.

Miami University, Oxford, O., Jan. 16.

\section{The Influence of Forests upon Rainfall and Climate.}

IN closing his valuable and interesting article in your paper of Jan. 6, entitled 'Do Forests influence Rainfall ?' Mr. Henry Gannett says, "With these results in view, it seems idle to discuss further the influence of forests upon rainfall from the economic point of view, as it is evidently too slight to be of the least practical importance."

Aside from the beneficial influence of forests in the retention and saving of the water which falls, may it not be that there is an effect of the forest upon climatic extremes of heat and cold? This is well shown, I think, by the experience of western Michigan. During the early years of the settlement of the country, before the forests were destroyed, all the delicate fruits of temperate climates were successfully grown.

Since the forests are nearly gone, the tender varieties of peaches can no longer be raised, except in a few favored localities, on account of extreme winter cold; and the heat of our summers has been of late years as extreme as the cold of our winters.

Holland, Mich., Jan. 9 . H. D. Post.

\section{Is there a Venomous Lizard?}

IN connection with the inquiry in Science of Jan. I3, as to the existence of a poisonous lizard (Heloderma), my own observations would corroborate the negative answer of your correspondent. I have had in my laboratory for five years a living specimen of the Gila monster (Heloderma suspectum), and during a portion of this time two specimens, both in healthy vigorous condition. In November, I883, I presented a communication to the Kansas Academy of Science, maintaining that this species is not venomous. I have repeatedly placed young kittens in the same cage with these reptiles, and have allowed them to remain together for a week at a time. During these times the kittens were frequently bitten ferociously by the lizards, but with no worse result than the temporary swelling of the part bitten from the mechanical effect of the powerful pressure. This was at first surprising to me, as intelligent miners in New Mexico had often informed me that the mere breath of this lizard was fatal to man.

Lawrence, Kan., Jan. 19.

\section{Queries.}

24. Silver Dollar in a Potato. - Is there any likelihood of the truth of the following story found in a recent New York paper? On Friday last a young woman was engaged in boiling some potatoes. She tested nearly all of the Irish apples, and found that they had been cooked to the proper consistency save one. This particular 'spud' remained as hard as adamant, and, although she allowed it to boil for fifteen minutes longer than the others, it showed no signs of yielding. At last she succeeded in splitting the vegetable open, and in the centre she found a silver dollar with the date of 1886 . The heart of the 'spud' was colored a blackish brown, but the outside presented a normal appearance. The silver dollar was black as ink.

\section{Answers.}

22. WASP-STINGS. - Bumble-bees and honey-bees, as well as 'wasps, may be safely taken in the hand while holding the breath, provided the experimenter will catch only males, which are easily recognized by their long antennæ and their face-colors. Have your correspondents been sure that they captured female wasps, which alone have stings? In the autumn the males are most plentiful, and in that season one may easily show an astonished companion how safely a wasp can be handled while holding one's breath, and afterwards while breathing also; but in doing this, I always take care to catch the right kind of wasp first. My faith in the supposed safeguard has never been sufficient to try the experiment intentionally with female Aculeata. Will not Mr. Safford make the test in the spring, and report his results once more? $\mathrm{He}$ will then doubtless agree with Life, that the most important thing in holding a wasp is how to let go. W. M. D.

Cambridge, Mass., Jan. 20. 